\title{
Meso-scale spatial variation in settlement and recruitment of intertidal barnacles along the coast of central Chile
}

\author{
Nelson A. Lagos ${ }^{1,2}$, Sergio A. Navarrete ${ }^{1, *}$, Fredy Véliz $^{1}$, Andrea Masuero ${ }^{1}$, \\ Juan C. Castilla ${ }^{1}$ \\ ${ }^{1}$ Estación Costera de Investigaciones Marinas and Center for Advanced Studies in Ecology and Biodiversity, \\ Pontificia Universidad Católica de Chile, Casilla 114-D, Santiago, Chile \\ ${ }^{2}$ Present address: Departamento de Ciencias Básicas, Universidad Santo Tomás, Ejército 146, Santiago, Chile
}

\begin{abstract}
Spatial and temporal variation in recruitment can be the leading determinant of population fluctuations in species with pelagic larval stages. Characterizing and identifying the causes of such variation is, therefore, necessary to understand population dynamics, and to develop conservation and management strategies. We examined spatial patterns in settlement and recruitment of the intertidal barnacles Jehlius cirratus, Notochthamalus scabrosus and Notobalanus flosculus, and their relationships with environmental variables operating at meso- (sea surface temperature, SST) and small (local topography) scales. Settlement and recruitment were studied over 6 mo at biweekly intervals at 16 sites along $120 \mathrm{~km}$ of coastline in central Chile. All species showed similar temporal patterns, with a peak in settlement and recruitment during austral spring. We decomposed the spatial patterns into their corresponding meso-scale trend (from a few to 10s of kilometers) and into their small-scale (site) residual variation. Recruitment of chthamaloid species was highly and positively correlated at meso- and small-scales, and the among-site rankings showed consistency of the spatial structure throughout the recruitment season. SST explained a significant fraction of the variance in recruitment of the chthamaloids at the meso-scale, and spatial analysis showed coincident decorrelation scales of about $35 \mathrm{~km}$ for SST and recruitment. In contrast, recruitment of balanoid species did not show a clear spatial structure, was not associated with meso-scale variation in SST, and local topography seemed to play a significant role in their settlement. Topographically modified upwelling dynamics over scales of $10 \mathrm{~s}$ of kilometers is the most plausible factor shaping meso-scale variation in recruitment of chthamaloid barnacles, whereas settlement and recruitment of balanoid species seem more strongly influenced by processes acting at local scales. The spatial scale and structure of recruitment provide guidelines for the placement and spacing of protected areas in the region.
\end{abstract}

KEY WORDS: Recruitment - Settlement - Barnacles · Spatial trend - Spatial autocorrelation · Upwelling · Topography

\section{INTRODUCTION}

The recruitment process has been recognized as one of the most important factors producing variability in population dynamics of benthic invertebrates with pelagic larval stages (Connell 1985, Gaines \& Roughgarden 1985, Roughgarden et al. 1988, Pineda 1994,
Sutherland 1990, Connolly \& Roughgarden 1998, Connolly et al. 2001, Eckert 2003). Consequently, studies designed to characterize the spatial scales at which recruitment shows greatest variation are necessary to understand population dynamics, and to develop conservation and management strategies (Botsford et al. 1998, Botsford 2001). 
Many studies have examined variation in benthic recruitment over relatively small spatial scales (Pineda 2000). From a few centimetres to several 10s of meters, studies have emphasized the role of larval arrival to the shore, as well as local topographic and microhabitat (including biological and chemical) conditions that can modify settlement behavior and enhance or reduce recruitment rates (LeTorneaux \& Bourget 1988, Guichard \& Bourget 1998, Jeffrey \& Underwood 2000). These studies have mostly focused on the process of settlement, when the larva makes permanent contact with the substratum and metamorphoses (Connell 1985), which usually lasts from a few hours to a few days. Due to logistical difficulties, few studies have attempted to characterize spatial variation in settlement and recruitment over meso(10s of kilometers) to large extensions (100s of kilometers) of coastal habitat (but see, Connolly \& Roughgarden 1998, Archambault \& Bourget 1999, Jenkins et al. 2000, Connolly et al. 2001, Navarrete et al. 2002). In most cases, these studies have focused on recruitment, which includes the survival of the settlers up to some visible stage, usually several days to weeks after settlement (Connell 1985). Results from these spatially extended studies have shown that variability in benthic recruitment may result from oceanographic factors or geomorphological features of the coastline, which directly or indirectly influence larval transport to shore. Wind-driven coastal upwelling, the relaxation of upwelling fronts, and their modification with coastline orientation have received particular attention as mechanisms producing meso-scale variation in larval transport and determining patterns of recruitment of invertebrates along the coast of California (Roughgarden et al. 1988, Ebert \& Russell 1988, Wing et al. 1995, 1998, Connolly \& Roughgarden 1998). However, there is scant information as to whether meso- or large-scale spatial patterns in recruitment are persistent over time, or whether taxonomically related species exhibit similar settlement and recruitment patterns along the shore.

Quantification of settlement and recruitment patterns can help to identify underlying causal processes affecting the supply of larvae to benthic populations. This is particularly important when the spatial or temporal scale of variation in the hypothesized driving process precludes experimental manipulations. For instance, the comparison of spatial patterns of recruitment among coexisting species could help evaluate hypotheses about the existence of common larval transport factors and provide insight into the spatial scale of the onshore transporting mechanism (Pineda 1994, Jenkins et al. 2000, Connolly et al. 2001, Navarrete et al. 2002). Regardless of the mechanisms involved, spatial patterns that persist over time and affect several species will produce large among-site differences in the supply of new individuals to local populations (Sutherland 1990, Camus \& Lagos 1996, Forde \& Raimondi 2004), which can suggest the scales of maximum variation in community dynamics (e.g. Connolly \& Roughgarden 1998, McKindsey \& Bourget 2000).

Moreover, information about the main spatial scales of variation in recruitment of intertidal species has important implications for conservation and management. For instance, a coherent spatial pattern or persistent ranking of sites for a suite of species would facilitate classification of sites as sources or sinks of larvae within the region (Botsford 2001), and provide guidelines for the placement of marine reserves. Additionally, determining the way in which the spatial correlation (see Legendre 1993) in recruitment changes with the geographical distance allows us to estimate the characteristic spatial scale (sensu Wiens 1989) at which recruitment occurs, which will be an indication of population connectivity (Botsford et al. 1998). This information is critical to identify, for instance, the optimum spacing among marine reserves.

In this study, we compare the spatial and temporal variation in recruitment of dominant intertidal barnacles and their association with meso-scale variation in upwelling intensity and local-scale variation in site topography along $120 \mathrm{~km}$ of coast in central Chile. The relatively low complexity of the coastline and the existence of oceanographic studies that have characterized patterns of upwelling intensity and sea surface temperature (SST) in the region (Castilla et al. 2002, Poulin et al. 2002, Kaplan et al. 2003, Wieters et al. 2003, Narváez et al. 2004, Nielsen \& Navarrete 2004, Vargas et al. 2004), provide an ideal setting to evaluate 4 working hypotheses: (1) settlement and recruitment of related barnacle species show similar patterns of spatial and temporal variation across the study region, (2) meso-scale trends in barnacle recruitment are well correlated with meso-scale variation in the intensity of coastal upwelling, and less correlated with local topography, (3) among-site differences in recruitment rates are persistent over time throughout the recruitment season and similar among species, and (4) within this region, spatial variation in recruitment and average SST show similar spatial structure and scale.

\section{MATERIALS AND METHODS}

Regional hydrography and geomorphology. The study was conducted at 16 wave-exposed intertidal sites along $120 \mathrm{~km}$ of the central Chile coastline (Fig. 1). The region is characterized by a narrow conti- 


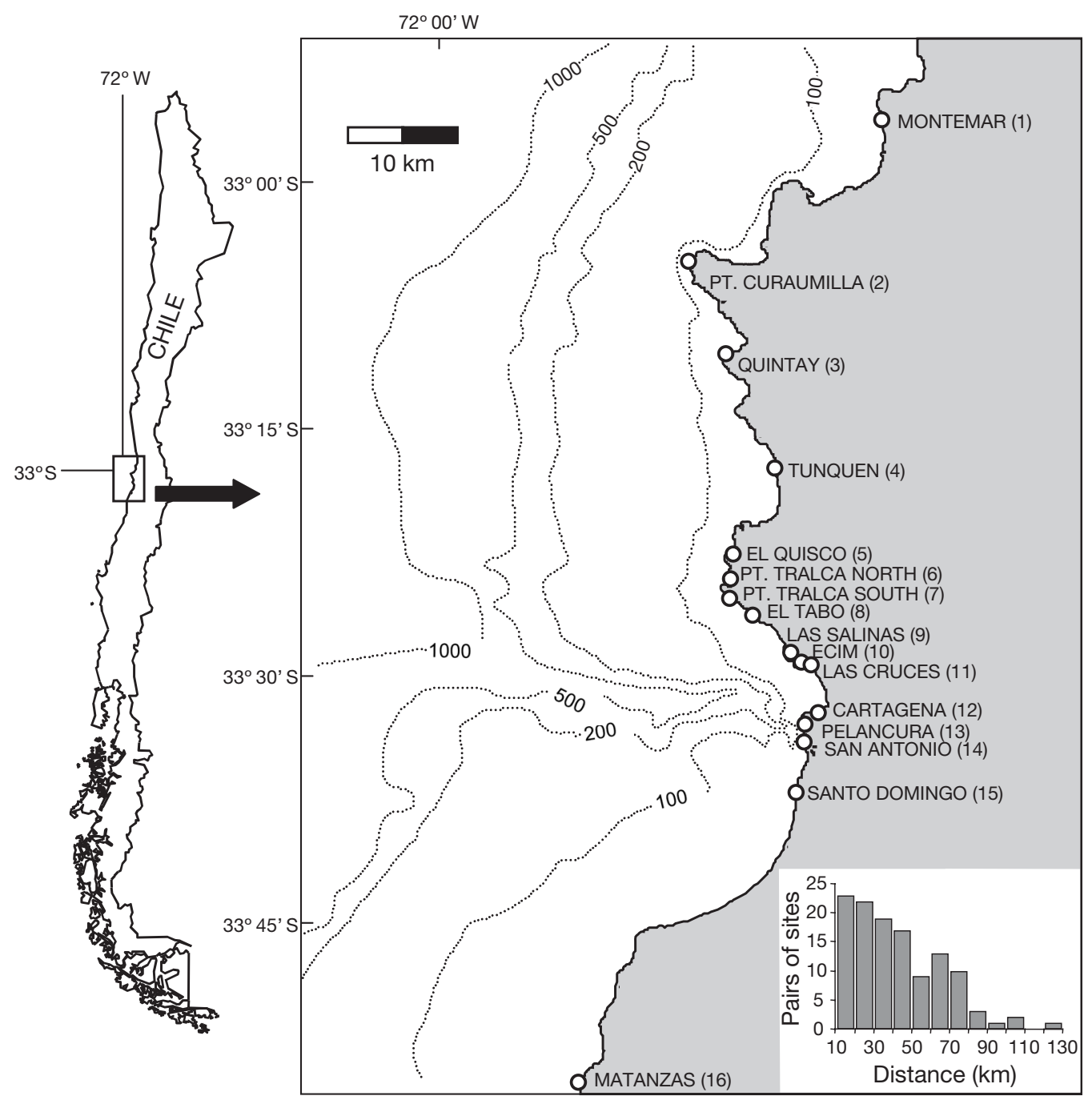

Fig. 1. Map of the coastline of central Chile (solid line) showing the location of the 16 study sites (circles). Dashed line indicates isobaths on the continental shelf. The insert shows the number of paired (between-site) comparisons by each distance class $(\mathrm{km})$ across the region. Numbers next to site names correspond with those used in Fig. 6

nental shelf, which becomes even narrower at the northern extreme of the region, near Point Curaumilla, and in the center of the region, near the submarine canyon in front of the San Antonio Port (Fig. 1). The tidal cycle is semidiurnal $(\sim 12.4 \mathrm{~h})$ and homogeneous across the region, with a range of approximately 1.83 $\mathrm{m}$ during the period of this study (SHOA 2002, Kaplan et al. 2003). Nearshore hydrography is dominated by wind-induced upwelling during austral spring and early summer (Strub et al. 1998, Poulin et al. 2002, see Fig. 2a). The process is intensified around capes and modified by coastline orientation, generating spatial variation in sea surface temperature (SST) over scales of a few to 10s of kilometres (Narváez et al. 2004). Within the study region, Point Curaumilla, Quintay and Matanzas (see Figs. 1 \& 2a) have been character- ized as areas of strong upwelling, while the site at El Quisco seems intermediate in upwelling intensity (Broitman et al. 2001, Nielsen \& Navarrete 2004). Adjacent to Las Cruces, there is an area of significantly warmer waters, apparently corresponding to an 'upwelling shadow' (sensu Graham \& Largier 1997) that may result from the forcing exerted from the Matanzas upwelling center (Castilla et al. 2002, Wieters et al. 2003, Narvaéz et al. 2004, Figs. 1 \& 2a). Thus, within the study region, the spring-summer pattern of SST measured at scales of days is dominated and inversely correlated with upwelling intensity (Poulin et al. 2002, Narváez et al. 2004). Besides the direct observations at these sites, there is no information about the spatial scales of the upwelling dynamics along the coast of central Chile. 
Barnacle recruitment. At all sites, we quantified recruitment of intertidal barnacles at biweekly intervals (mean $\pm 2 \mathrm{SE}=15.2 \pm 0.3 \mathrm{~d}$ ) between August 2002 and January 2003, encompassing the typical season of barnacle recruitment in central Chile (Navarrete et al. 2002). At the mid (approximately 60 to $80 \mathrm{~cm}$ above MLLW) and low (20 to $40 \mathrm{~cm}$ above MLLW) intertidal zones of each site, we deployed 4 Plexiglas ${ }^{\circledR}$ plates $(10 \times 10 \mathrm{~cm})$ covered with safety-walk $\left(3 \mathrm{M}^{\oplus}\right)$, spread along a 10 to $30 \mathrm{~m}$ long transect, parallel to the coastline of a wave-exposed rocky bench. The safety-walk is a rubbery, rough, gray-color, self-adhesive tape, commercially provided as floor cover for boats, which provides a standard surface rugosity across plates and sites, and is commonly used in barnacle recruitment studies (Farrell et al. 1991, Menge et al. 1994, Menge 2000, Navarrete et al. 2002). At each sampling time, plates were brought to the laboratory for analysis under a dissecting microscope and replaced with new ones. Depending on weather conditions, plates were replaced with a maximum lag of $5 \mathrm{~d}$ among sites.
The 3 most abundant barnacle species inhabiting the intertidal zone along the Chilean coast were observed on the plates, the chthamaloids Jehlius cirratus and Notochthamalus scabrosus, and the balanoid Notobalanus flosculus (previously Balanus flosculus, Camus \& Lagos 1996, Navarrete et al. 2002). Pelagic larval duration from nauplius to cypris stages of $\mathrm{J}$. cirratus and $N$. scabrosus varies between 22 and $29 \mathrm{~d}$ at 18 to $20^{\circ} \mathrm{C}$, and between 39 and $41 \mathrm{~d}$ at 15 to $18^{\circ} \mathrm{C}$ (Venegas et al. 2000). There is no published information about larval duration in N. flosculus. Laboratory experiments suggest that larval duration in N. flosculus is similar or slightly longer than that of the 2 chthamaloid species, with a duration of ca. $39 \mathrm{~d}$ at 18 to $20^{\circ} \mathrm{C}$ (A. Olguin \& S. A. Navarrete unpubl. data). Premetamorphic cyprids were also observed on the plates and counted separately, but could not safely be identified to the species level and were classified as either chthamaloid or balanoid. This biweekly estimate of settlement from cyprid numbers must be interpreted with some caution, since it only considers larvae
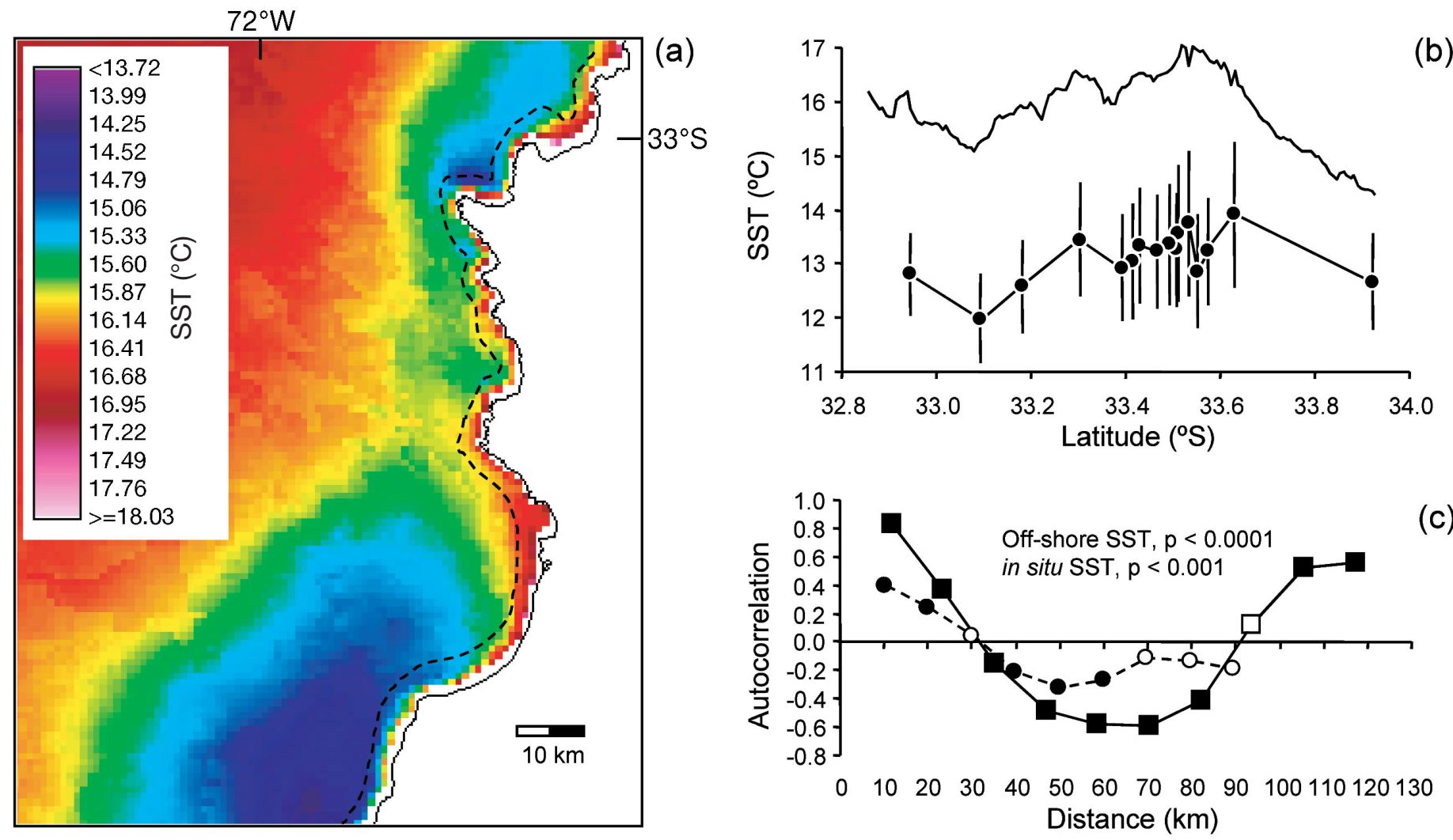

Fig. 2. (a) Spatial variation in sea surface temperature (SST) derived from AVHRR satellite images during 4 upwelling seasons. Dashed line illustrates the transect position to extract the offshore SST. (b) Latitudinal variation in offshore SST (solid line) and in situ measured SST at each study site (mean \pm SD; $\bullet$ ). (c) Spatial correlograms for satellite $(\square, \boldsymbol{\bullet}$, Moran's I index) and in situ (O, $\bullet$, dashed line, Mantel index) SST measurements along the coast. For both indices, positive and negative values indicate positive and negative spatial correlation, respectively. The horizontal line represents the expected values under the null hypothesis of no spatial autocorrelation, and the distance at which the autocorrelation intersects the horizontal line corresponds to the decorrelation or characteristic spatial scale. Filled symbols indicate significant correlations after sequential Bonferroni correction and p values indicate Bonferroni-corrected significance for both overall Moran and Mantel correlograms 
settled within the previous 1 to $2 \mathrm{~d}$ from replacement of plates (Venegas et al. 2000, S. A. Navarrete unpubl. obs.).

Adult abundances. Surveys were conducted using ten $50 \times 50 \mathrm{~cm}$ quadrats randomly positioned along a 20 to $40 \mathrm{~m}$ long transect, parallel to the coastline at each tidal level (mid and low) and on 2 separate benches, 30 to $100 \mathrm{~m}$ apart, at each study site. In these surveys, we measured density of all mobile and cover of all sessile species through direct counts of individuals and through the intersection point method (81 points regularly spaced), respectively. Here, we only analyze the mean cover of barnacle species per site to evaluate correlations with recruitment. Results from these surveys will be presented elsewhere.

Environmental variables. We selected platforms to be similar across the region in exposure to wave action (e.g. maximum water velocity between 6.2 to $8.7 \mathrm{~m} \mathrm{~s}^{-1}$, Castilla et al. 1998) and general topographic characteristics (e.g. rock type, inclination), but some differences were inevitable. To determine whether variation in recruitment among sites could be explained in part by uncontrolled variation in local topography among benches, we quantified the heterogeneity, slope and orientation of all benches. The ratio, $H=I / L$, was used as a descriptor of the bench heterogeneity, where $I$ is the total length measured using an iron chain of $1.5 \mathrm{~cm}$ links, lined over the rock contour surface, and $L$ is the minimum linear distance between the extremes of the bench. For a smooth surface, $H=1$ and increases with increasing heterogeneity of scales $>$ ca. $5 \mathrm{~cm}$ (Archambault \& Bourget 1996). The average of 6 measures of $H$ taken at each bench, 2 parallel (horizontal) and 4 perpendicular to the water level (vertical), was used as an indicator of local heterogeneity. The slope of each bench was measured at 6 to 10 positions using a level and a $1 \mathrm{~m}$ long graduated angle scale. The orientation with respect to geographical north was determined for sections 20 to $50 \mathrm{~m}$ long of each bench using a Suunto ${ }^{\circledR}$ compass. Additionally, we deployed temperature loggers (Tidbit Stowaway, ONSET) at about $1 \mathrm{~m}$ depth at each site, which recorded SST (hereafter in situ SST) at $5 \mathrm{~min}$ intervals. Since high-frequency variation in temperature is not directly correlated with upwelling activity (Kaplan et al. 2003, Vargas et al. 2004), we first averaged all observations to obtain daily means for each of the 16 sites.

Data analyses. A 3-way ANOVA on temporal averages, with species and tidal level as fixed factors, and sites as a random factor, was used to evaluate the consistency of among sites and between species differences across the study region. As low values of recruitment (zeroes) occurred for all species outside the peak recruitment season (see 'Results'), we only analyzed the temporal window from mid-October to mid-December. A similar statistical analysis was performed on cyprid settlement. In all cases, a $\log _{10}$ $(\mathrm{n}+1)$ transformation was applied to meet ANOVA assumptions. As Notochthamalus scabrosus and Notobalanus flosculus showed large significant differences in recruitment between tidal levels (see 'Results'), we selected the tidal level of higher mean abundance for further analyses, which in both cases corresponded to the low tidal zone. In the case of Jehlius cirratus, which did not show differences between tidal levels, the average abundance across tidal levels was used. In the case of settlement of chthamaloid and balanoid cyprids, the average abundance across tidal levels was used.

To distinguish spatial correlation resulting from spatial trends in barnacle recruitment from those due to site-to-site variation, we decomposed the spatial variation in barnacle recruitment into its trend (i.e. spatial variation common to several sites adjusted throughout the study region) and the residual variation (local variation not accounted by the trend). A LOcally WEighted Scatterplot Smoothing (LOWESS; Cleveland 1979) was fitted to the spatial pattern in recruitment $(\log n+1)$ as a function of the relative distance with respect to the southernmost site of the study array (Matanzas, Fig. 1). The process was repeated for several values of the $f$-factor (or tension) to address the problem of how much smoothing is allowed due to the subjectivity in its selection (Trexel \& Travis 1993). The $f$-factor selected for analysis was that producing normal LOWESS residuals and independence from geographical distance (Kolmogorov-Smirnov tests, p > 0.05; Trexel \& Travis 1993). In each LOWESS regression, we retained the predicted recruitment values for each focal point (Ys) and the local residuals; then, we calculated the correlations among species using $r$ Pearson correlations for the 3 descriptors of barnacle recruitment rate: (1) the fitted LOWESS values (hereafter, the meso-scale trend), (2) the local residuals (hereafter, small-scale variation) and (3) the observed mean recruitment at the site (hereafter, raw data). Similar analyses were performed for cyprid settlement. A Bonferroni correction was applied to adjust significance levels for multiple comparisons (Legendre \& Legendre 1998).

We used linear simple and multiple regression analyses to evaluate the effects of local variation in platform slope, heterogeneity and in situ SST on the spatial pattern described by the 3 descriptors of barnacle recruitment. For bench orientation (measured in degrees), we used the linear-circular regression model: $R=b_{0}+$ $b_{1} \cos a_{\mathrm{i}}+b_{2} \sin a_{\mathrm{i}}$, where $R$ is the linear descriptor of barnacle recruitment, $a$ is the platform orientation 
(circular variable), and $b_{0}, b_{1}$ and $b_{2}$ are the regression coefficients (Zar 1999). A similar analysis was performed to determine the influence of these environmental variables on cyprid settlement. Additionally, we analyzed the spatial pattern of SST obtained as a weighted average of 62 NOAA-AVHRR satellite images encompassing 4 different upwelling seasons (September to January of 1992-1993, 1997-1998, 1999-2000 and 2000-2001). These historical images were previously selected and averaged by Narváez et al. (2004). Using image-processing techniques (see Lagos et al. 2002), we extracted a transect, parallel to the shoreline about 3 to $4 \mathrm{~km}$ offshore (hereafter, offshore SST). A spatial autocorrelation analysis using Moran's index (Sokal \& Oden 1978) and 10 evenly spaced distance classes were then used to determine the characteristic scale of variation in offshore SST across the study region, using SAAP v4.3 software (Wartenberg 1989). Results obtained from the satellite images were compared against the spatial pattern measured by in situ loggers. To this end, using the entire daily time series, we calculated the temporal correlation between all pairs of sites and examined the spatial structure of this correlation matrix against the matrix of Euclidean distances among sites with a Mantel test (Mantel 1967). A Mantel correlogram was then constructed using 8 evenly spaced distance classes (11 km) and pooling in a single class pairs of sites separated by distances between 90 and $120 \mathrm{~km}$. Due to the multiple comparison among sites, the significance of the overall Mantel test and corresponding correlogram was assessed through 1000 permutations of the geographical distance matrix (Legendre \& Legendre 1998).

To determine the persistence of the spatial pattern over the recruitment season, sites were ranked in descending order from the one with the highest (rank = 15) to the lowest (rank $=0$ ) recruitment at each sampling date, considering only dates within the recruitment season (see 'Results'). Ranks were then averaged across sampling dates and plotted against average recruitment rate per site. Although the average ranking of sites and the overall mean recruitment rate are not independent, variation in the strength of the correlation among species is indicative of the relative persistence of the spatial pattern through time. A Spearman rank correlation was used to compare the average ranking of sites among barnacle species. Spatial autocorrelation analyses using Moran's index and 10 evenly spaced distance classes of $11 \mathrm{~km}$ were used to characterize the scale of variation in the average ranking of sites for each barnacle species. Smaller distance classes were not chosen for these analyses, because they would excessively weight the closer sites located towards the center of the region (Fig. 1). Previously, data were normalized removing the average and dividing by the standard deviation, and the significance of the overall spatial correlogram was corrected using a Bonferroni approximation (Legendre \& Legendre 1998). Due to the inevitable loss of degrees of freedom towards greater distances (see insert in Fig. 1), we did not interpret distances $>80 \mathrm{~km}$. Moreover, to determine the sensibility of the spatial trends to the smaller spacing of sites towards the center of the region, we repeated the spatial autocorrelograms with (1) all sites (as described above), (2) removing 3 sites and (3) removing 3 pairs of adjacent sites (6 sites removed) from the center of the region to increase their spacing.

\section{RESULTS}

The temporal pattern in recruitment of all barnacles was characterized by a strong increase from mid-October to mid-December, and nearly nil recruitment the rest of the year (Fig. 3), rendering significant positive temporal correlations among species (Table 1a). The LOWESS smoothing (with tension factor, $f=0.5$ ) showed that, during the recruitment season, rates of Jehlius cirratus and Notochtamalus scabrosus recruitment were characterized by an increase in the center of the study region, between Pelancura and Punta de Tralca, and slightly lower rates towards the northern than towards the southern extreme of the region (Fig. 3). Recruitment of Notobalanus flosculus also showed a peak in the center of the region, but recruitment increased again towards both extremes of the study region (Fig. 3).

Differences in overall recruitment rates among species depended on tidal level (significant species $\times$ level interaction in Table 2a), but were consistent across sites (no significant 3-way interaction term, Table 2a). While Jehlius cirratus recruited at similarly high rates in the mid and low intertidal zones, Notochthamalus scabrosus and Notobalanus flosculus recruitment was significantly higher in the low than the mid shore (Tukey's test among species by tidal level, $\mathrm{p}<0.05$, Fig. 4a). Highly significant differences in recruitment rates were observed among sites, and these differences were consistent across species and across tidal levels (Table 2a). A similar temporal and spatial pattern was observed in cyprid settlement, with a peak in November (Fig. 5) and increased abundance at sites towards the center of the region (Fig. 5). Significant and consistent differences in cyprid settlement were observed among sites and, as expected from the observed tidal differences in recruitment of the species, differences between chthamaloid and balanoid settle- 

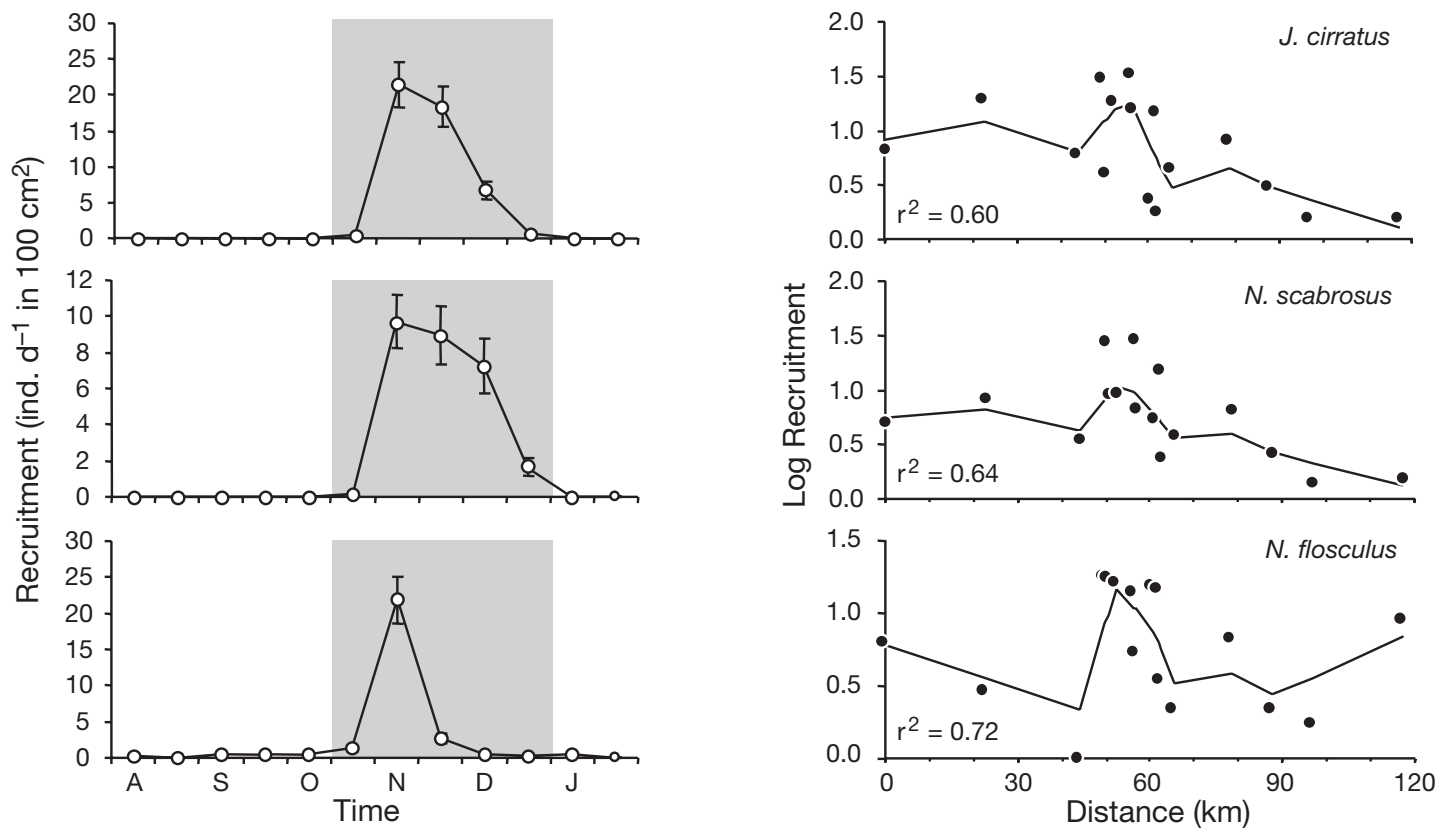

Fig. 3. Jehlius cirratus, Notochthamalus scabrosus and Notobalanus flosculus. Temporal (left panels) and spatial (right panels) patterns in recruitment rate of intertidal barnacles. Spatial pattern is represented as a function of the distance with respect to the southernmost study site (Matanzas). •: average recruitment; solid line: LOWESS smoothing. The ${ }^{2}$ value corresponds to the LOWESS fit. The shaded area in temporal pattern indicates the window of time used in further spatial analyses (see 'Materials and methods')

ment depended on tidal level (Table 2b); however, within barnacle taxa, differences in cyprid abundance between tidal levels were not significant (Tukey's test, p > 0.05, Fig. 4b).

Table 1. Among-species correlation coefficients comparing: (a) the temporal mean (pooled across sites, $\mathrm{n}=16$ ) in barnacle recruitment, (b) the spatial mean recruitment (pooled across dates, $\mathrm{n}=5$ ), (c) the meso-scale spatial trend (fitted values of LOWESS regression), (d) the small-scale variation (LOWESS residuals) across the region and (e) the averaged ranking in recruitment per site across the region. All estimates of spatial variation in recruitment rate are based on 5 sampling dates from October to December 2002, while temporal variation encompasses all sampling dates. Bold: significant linear correlation after Bonferroni correction. ${ }^{* * *} \mathrm{p}<0.001{ }^{*}{ }^{* *} \mathrm{p}<0.01$; ${ }^{*} \mathrm{p}<0.05$; ns: $\mathrm{p}>0.05$

\begin{tabular}{|lllc|}
\hline \multirow{2}{*}{$\begin{array}{l}\text { Recruitment } \\
\text { descriptor }\end{array}$} & & \multicolumn{2}{c|}{ Correlation } \\
\hline $\begin{array}{c}\text { (a) Temporal } \\
\text { pattern }\end{array}$ & N. scabrosus & $\mathbf{0 . 9 5}^{* * *}$ & - \\
(b) Meso-scale & N. scabrosus & $\mathbf{0 . 7 8}^{* *}$ & $\mathbf{0 . 6 5}^{*}$ \\
trend & N. flosculus & $\mathbf{0 . 9 7}^{* * *}$ & - \\
(c) Raw data & N. scabrosus & $0.88^{* * *}$ & - \\
& N. flosculus & $0.38 \mathrm{~ns}$ & $\mathbf{0 . 6 1 ^ { * }}$ \\
(d) Small-scale & N. scabrosus & $\mathbf{0 . 7 3}^{* * *}$ & - \\
variation & N. flosculus & $0.19 \mathrm{~ns}$ & $\mathbf{0 . 6 8}$ \\
(e) Averaged & N. scabrosus & $\mathbf{0 . 8 6}$ & - \\
ranking & N. flosculus & $0.46 \mathrm{~ns}$ & $0.45^{*}$ \\
\hline
\end{tabular}

The spatial pattern of recruitment was significantly correlated among the 3 barnacle species when considering the meso-scale LOWESS adjusted trend in the data (all spatial correlations were significant at Bonferroni corrected $\alpha^{\prime}=0.025$, Table 1b). Overall, weaker among-species correlations were observed

Table 2. Three-way ANOVA comparing (a) barnacle recruitment and (b) cyprid settlement rate across species, sites and intertidal levels, averaged over 5 sampling dates, from mid-October to mid-December 2002. Bold: significant effects at $\alpha=0.05$

\begin{tabular}{|lrcrrc|}
\hline Source of variation & df & SS & MS & $F$ & $\mathrm{p}$ \\
\hline (a) Recruitment & & & & & \\
Species & 2 & 20.041 & 10.02 & 9.28 & $\mathbf{0 . 0 0 0 7}$ \\
Site & 15 & 84.55 & 5.64 & 4.80 & $<\mathbf{0 . 0 0 0 1}$ \\
Level & 1 & 10.72 & 10.72 & 23.58 & $\mathbf{0 . 0 0 0 2}$ \\
Species $\times$ Site & 30 & 32.38 & 1.08 & 0.92 & 0.5910 \\
Species $\times$ Level & 2 & 7.04 & 3.52 & 11.43 & $\mathbf{0 . 0 0 0 2}$ \\
Site $\times$ Level & 15 & 6.82 & 0.45 & 0.39 & 0.9819 \\
Species $\times$ Site $\times$ Level & 30 & 9.23 & 0.31 & 0.26 & 1.0000 \\
(b) Settlement & & & & & \\
Group & 1 & 0.052 & 0.052 & 0.71 & 0.4116 \\
Site & 15 & 4.72 & 0.31 & 1.93 & $\mathbf{0 . 0 2 0 6}$ \\
Level & 1 & 0.43 & 0.43 & 4.88 & $\mathbf{0 . 0 4 3 2}$ \\
Group $\times$ Site & 15 & 1.09 & 0.07 & 0.45 & 0.9636 \\
Group $\times$ Level & 1 & 0.43 & 0.43 & 14.53 & $\mathbf{0 . 0 0 1 7}$ \\
Site $\times$ Level & 15 & 1.33 & 0.08 & 0.55 & 0.9121 \\
Group $\times$ Site $\times$ Level & 15 & 0.44 & 0.03 & 0.18 & 0.9997 \\
\hline
\end{tabular}



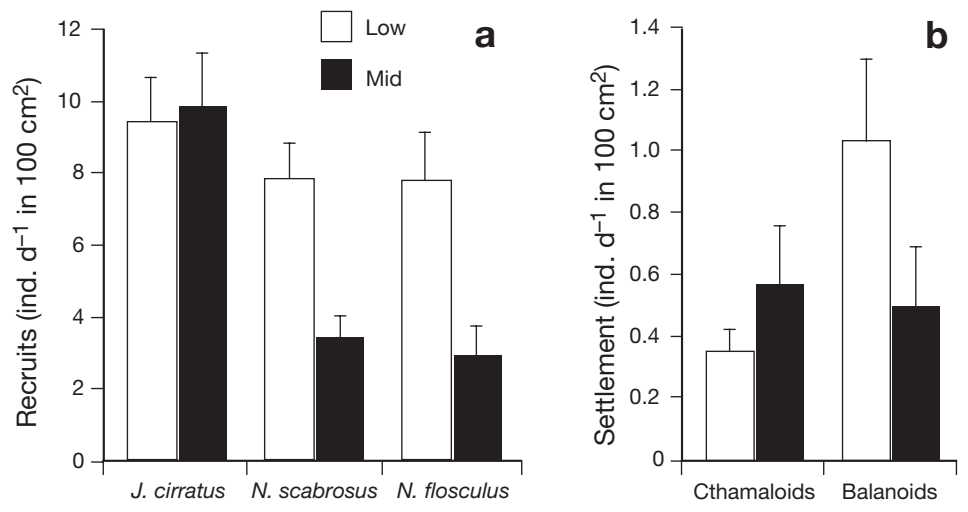

Fig. 4. Jehlius cirratus, Notochthamalus scabrosus and Notobalanus flosculus. Patterns of abundance of (a) barnacle recruitment and (b) settlement of cyprids at 2 tidal levels during the temporal window from October to December 2002. Data averaged across sites (mean + SE)

when considering either raw data or small-scale residual variation, with non-significant correlations between Jehlius cirratus and Notobalanus flosculus (Table 1c,d). Similarly high and significant correlation of the meso-scale spatial trend was observed between chthamaloid and balanoid cyprids ( $r=0.58, \mathrm{p}=0.018)$, while at the small-scale, spatial variation was not statistically associated between these barnacle taxa $(r=0.41, \mathrm{p}=0.118)$.

The spatial variation in local heterogeneity, slope and orientation were not associated among sites, indicating idiosyncratic properties of each study site platform. Although in situ measured SST was almost $3^{\circ} \mathrm{C}$ colder than offshore SST obtained from satellite b images, both measures were positively and significantly associated (Pearson's $r=0.59$, $\mathrm{p}=0.017, \mathrm{n}=16$, Fig. 2b). SST adjacent to the study site represent cold water upwelled at the border of the continent, while SST recorded by satellite is ca. 2 to $3 \mathrm{~km}$ offshore, and thus heat transfer from the atmosphere and solar radiation increase the temperature as the water moves offshore. In addition, temperature retrieval by the satellite sensor is dependent on atmospheric conditions (Lagos et al. 2002). The pattern of offshore SST during upwelling seasons showed significant spatial structure, with positive correlations among sites separated by $<30 \mathrm{~km}$, negative correlations among sites separated by 35 and up to $90 \mathrm{~km}$, and positive correlation again at distances $>100 \mathrm{~km}$ (Fig. 2c). Short-distance positive correlations may reflect similitude in SST within upwelling and non-upwelling areas, while meso-scale negative correlations may reflect the differences between these contrasting oceanographic regimens. Positive correlations at distances $>100 \mathrm{~km}$ may result from similitude in the SST among the upwelling areas located at the extremes of the region (i.e. Matanzas and Curaumilla, Fig. 1). Similar spatial structure was evident for in situ measured SST at the study sites, when using the cross-correlations among daily temperature time series for each site (Fig. 2c); i.e. positive correlations among sites separated by $<30 \mathrm{~km}$ and negative correlations from 40 to about $60 \mathrm{~km}$ (Fig. 2c).
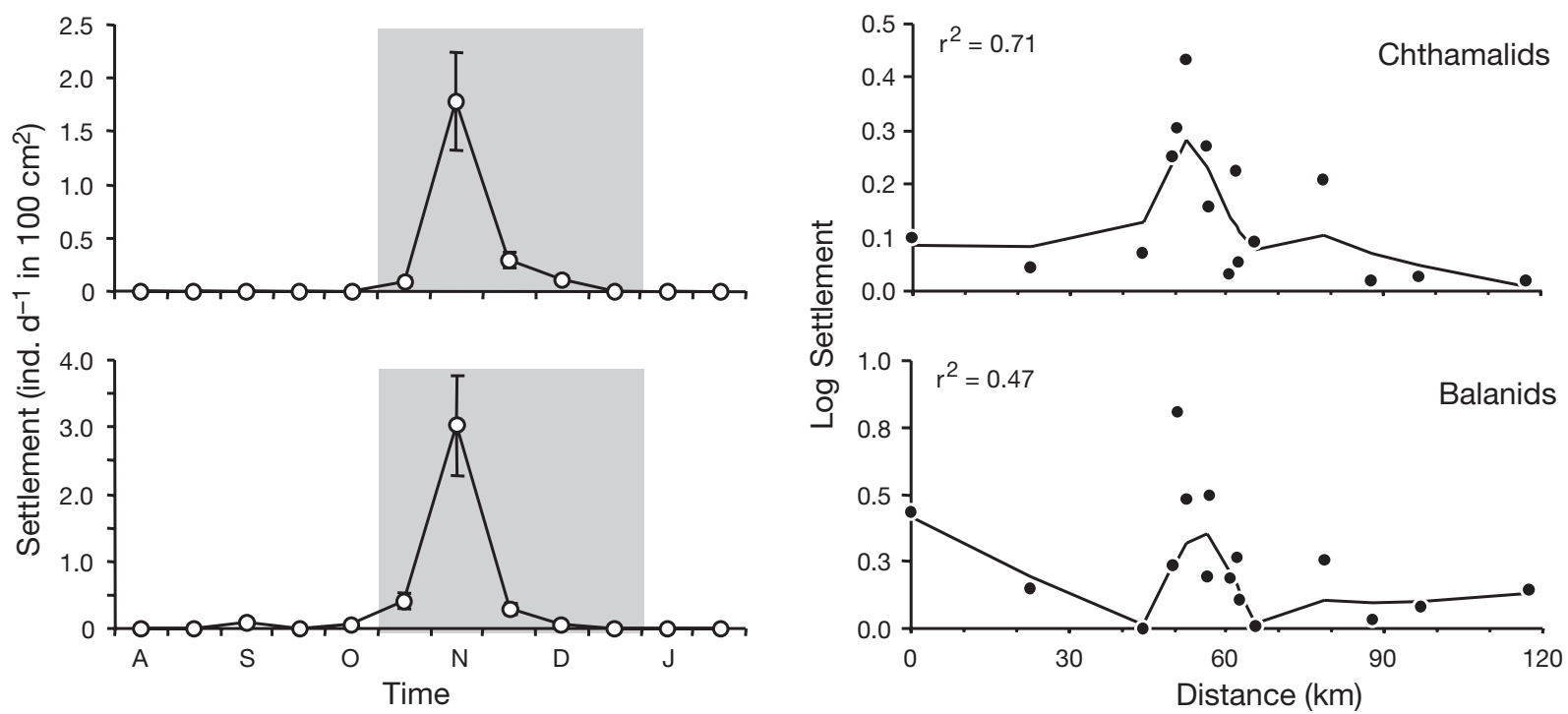

Fig. 5. Temporal (left panels) and spatial (right panels) patterns in cyprid settlement. Spatial pattern is represented as a function of the distance with respect to the southernmost study site (Matanzas). •: average settlement; solid line: LOWESS smoothing. The $\mathrm{r}^{2}$ value corresponds to the LOWESS fit of the model. The shaded area in temporal pattern indicates the window of time used in further spatial analyses (see 'Materials and methods') 
Simple linear regression analyses showed that variation in local topography of the study site does not account for significant spatial variation in any descriptor of recruitment (raw data, meso-scale trend or smallscale residual variation) of any barnacle species. In contrast, in situ SST accounted for a high and significant proportion of the trend for both raw data and the meso-scale trend in recruitment of Jehlius cirratus and Notochthamalus scabrosus, but not for the residual, small-scale variation (Table 3a). A similar result was observed for the meso-scale trend in settlement of chthamaloid cyprids (Table 3b). On the other hand, neither recruitment of Notobalanus flosculus nor settlement of balanoid cyprids was associated with SST, but local slope and orientation explained a significant portion of the small-scale, residual variation in settlement of balanoid cyprids (Table 3b). Results from multiple linear regressions including heterogeneity, slope and in situ SST showed the same patterns. SST explained a significant fraction of the meso-scale trend in recruitment of J. cirratus and N. scabrosus (partial $\mathrm{R}^{2}=0.392$ and $0.422, \mathrm{p}=0.014$ and 0.010 , respectively) and settlement of chthamaloid cypris (partial $\mathrm{R}^{2}=0.419, \mathrm{p}=$ 0.012 ), but not $N$. flosculus (partial $\mathrm{R}^{2}=0.221, \mathrm{p}=$ 0.084 ) or settlement of balanoid cypris (partial $\mathrm{R}^{2}=$ $0.121, p=0.207$ ). Local heterogeneity only explained a significant fraction of residual, small-scale variation in recruitment of $N$. flosculus and settlement of balanoid cypris (partial $\mathrm{R}^{2}=0.291$ and $0.283, \mathrm{p}=0.029$ and 0.012 , respectively), and slope was only significant in the small-scale variation in settlement of balanoid cypris (partial $\mathrm{R}^{2}=0.158, \mathrm{p}=0.047$ ).
To shed light on the influence of post-settlement factors on recruitment patterns, we examined the relationship between settlement and recruitment at the highest peak in settlement across the region (November 2002). The abundance of cyprids on the plates at each site was positively and significantly correlated to the recruitment recorded for the corresponding $15 \mathrm{~d}$ interval between sampling dates for Jehlius cirratus (r $=0.8, \mathrm{p}<0.0001)$, Notochthamalus scabrosus $(\mathrm{r}=0.69$, $\mathrm{p}=0.003$ ) and Notobalanus flosculus $(\mathrm{r}=0.58, \mathrm{p}=$ 0.017). To examine the relationship between local adult abundance and recruitment, we calculated Pearson and Spearman rank correlations between average recruitment rate by site and average adult cover. No significant correlation was found for chthamaloid barnacles (Pearson's $\mathrm{r}<0.20, \mathrm{p}>0.45$, Spearman's rank $\mathrm{r}_{\mathrm{S}}$ $<0.26$, p > 0.31, for all comparisons). However, a significant correlation was found for $N$. flosculus using either linear Pearson or rank correlations $(\mathrm{r}=0.68, \mathrm{p}=$ 0.0038), showing that sites with higher recruitment also had higher adult cover of this species.

As expected, the relationship between local recruitment and the averaged ranking of that site throughout the recruitment season was positive for all species, but the strength of the relationship was much weaker for Notobalanus flosculus than for chthamaloid species (Fig. 6). This means that the spatial pattern of recruitment was consistent over time for Jehlius cirratus and Notochthamalus scabrosus, and more variable for $N$. flosculus. For all species, the highest rankings were consistently observed in the center of the study region, namely at ECIM, Pelancura and Las Cruces, where the

Table 3. Explained variation $\left(\mathrm{r}^{2}\right)$ in the relationship between spatial descriptors of (a) barnacle recruitment and (b) cyprid settlement with heterogeneity, slope and orientation of the local platforms $(\mathrm{n}=16)$ and in situ surface temperature (SST). Bold: significant linear relationship $(\mathrm{p}<0.05)$

\begin{tabular}{|c|c|c|c|c|c|}
\hline \multirow{2}{*}{ Taxon } & \multirow[b]{2}{*}{ Spatial descriptor } & \multirow[b]{2}{*}{ Heterogeneity } & \multicolumn{2}{|c|}{ Environmental variable } & \multirow[b]{2}{*}{ In situ SST } \\
\hline & & & Slope & Orientation $^{\mathrm{a}}$ & \\
\hline \multicolumn{6}{|c|}{ (a) Barnacle recruitment } \\
\hline \multirow[t]{3}{*}{ J. cirratus } & Raw data & 0.068 & 0.130 & 0.230 & 0.256 \\
\hline & Meso-scale trend & 0.030 & 0.007 & 0.080 & 0.392 \\
\hline & Small-scale variation & 0.040 & 0.229 & 0.210 & 0.005 \\
\hline \multirow{3}{*}{ N. scabrosus } & Raw data & 0.004 & 0.040 & 0.170 & 0.290 \\
\hline & Meso-scale trend & 0.030 & 0.007 & 0.065 & 0.410 \\
\hline & Small-scale variation & 0.005 & 0.060 & 0.180 & 0.041 \\
\hline \multirow[t]{3}{*}{ N. flosculus } & Raw data & 0.080 & 0.020 & 0.040 & 0.140 \\
\hline & Meso-scale trend & 0.030 & 0.008 & 0.020 & 0.099 \\
\hline & Small-scale variation & 0.090 & 0.020 & 0.080 & 0.103 \\
\hline \multicolumn{6}{|c|}{ (b) Cyprid settlement } \\
\hline \multirow{3}{*}{ Chthamaloids } & Raw data & 0.020 & 0.000 & 0.020 & 0.239 \\
\hline & Meso-scale trend & 0.012 & 0.001 & 0.006 & 0.259 \\
\hline & Small-scale variation & 0.014 & 0.002 & 0.030 & 0.078 \\
\hline \multirow[t]{3}{*}{ Balanoids } & Raw data & 0.040 & 0.050 & 0.250 & 0.209 \\
\hline & Meso-scale trend & 0.012 & 0.050 & 0.060 & 0.056 \\
\hline & Small-scale variation & 0.040 & 0.250 & 0.450 & 0.196 \\
\hline \multicolumn{6}{|c|}{${ }^{\mathrm{a}}$ Linear-circular regression } \\
\hline
\end{tabular}



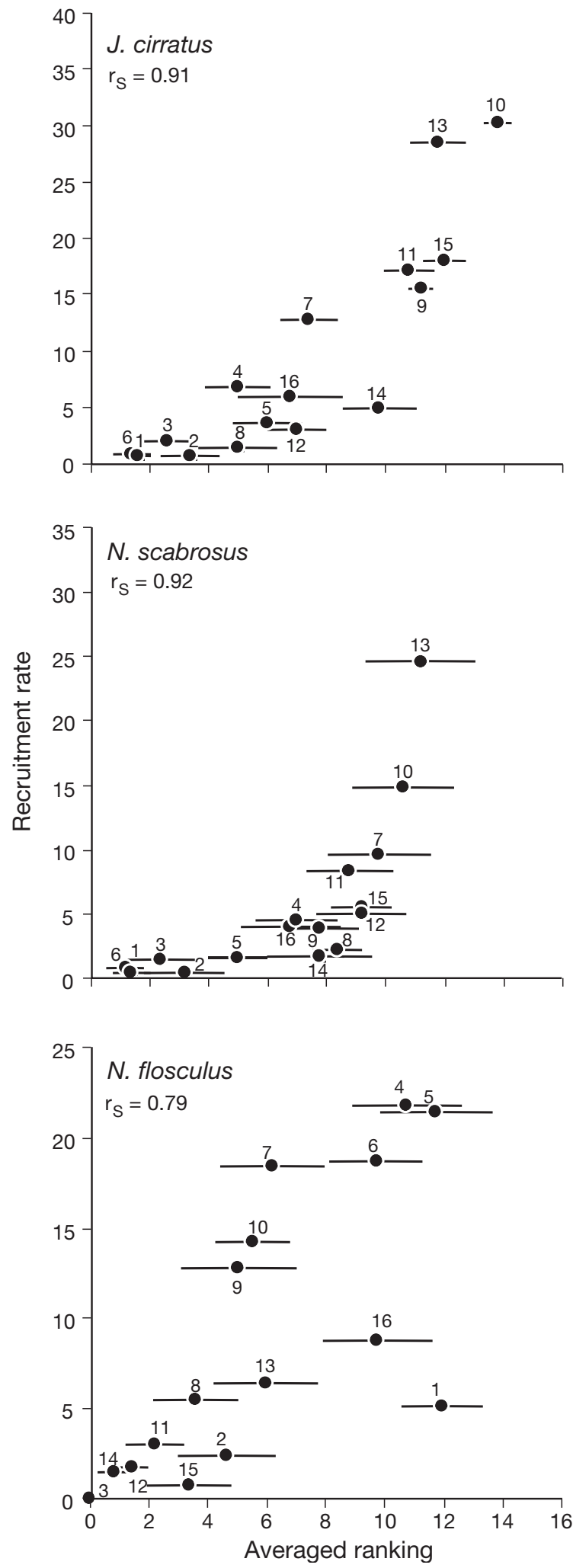

Fig. 6. Jehlius cirratus, Notochthamalus scabrosus and Notobalanus flosculus. Relationship between mean recruitment rate and the corresponding averaged ranking $( \pm \mathrm{SE})$ in recruitment of intertidal barnacles. Numbers represent study sites, as in Fig. 1 highest mean recruitment rates were also observed (see Figs. 1 \& 3). The main differences between $N$. flosculus and the other species occurred at Montemar, where recruitment of the former species was relatively low, but highly persistent over time (Fig. 6). These differences among species were reflected in significant positive association between the averaged ranking of $N$. scabrosus and $J$. cirratus, but not between $N$. flosculus and the other species (Table 1e). Spatial autocorrelation analyses of the average rank of sites showed different patterns between $N$. flosculus and the other barnacle species (Fig. 7). In the case of J. cirratus and N. scabrosus, the spatial structure exhibited clinal variation, with positive and significant correlations among sites separated $<35 \mathrm{~km}$ and negative correlations among sites separated by 45 and up to $90 \mathrm{~km}$ (Fig. 7). This pattern produced a decorrelation scale (i.e. the distance at which Moran's $I$
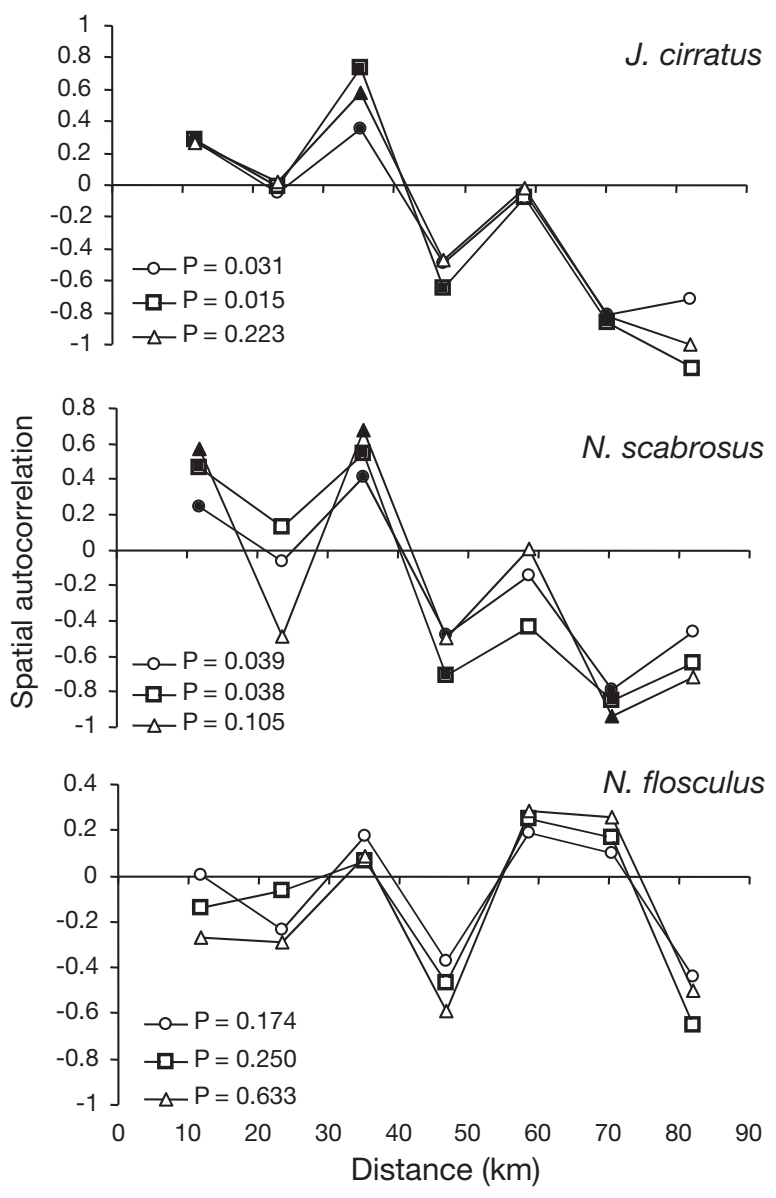

Fig. 7. Jehlius cirratus, Notochthamalus scabrosus and Notobalanus flosculus. Spatial correlograms (Moran's I autocorrelation index as a function of the distance separating the sites) of the average ranking in recruitment of intertidal barnacles, including all sites in the analysis $(\bullet)$, removing 3 sites $(6,11$ and 13 in Fig. 1, $\square)$ and removing 6 adjacent sites $(6-7,9-10$, 12-13 in Fig. 1, $\mathbf{\Delta}$ ). Filled symbols indicate significant correlations at that distance class; the $\mathrm{p}$ values indicate Bonferronicorrected significance for the overall correlogram 
passes from positive to negative values) between approximately 35 to $45 \mathrm{~km}$. In the case of $N$. flosculus, the correlogram for average rankings was flat, with no clear spatial structure (Fig. 7). In all cases, the correlograms were highly robust to spatial differences in sampling intensity across the region, either removing 3 or 6 sites from the center of the region (Fig. 7).

\section{DISCUSSION}

The chthamaloid barnacles Jehlius cirratus and Notochthamalus scabrosus and the balanoid Notobalanus flosculus showed strikingly similar temporal patterns of recruitment and similar meso-scale spatial trends along the $120 \mathrm{~km}$ of coastline covered by this study. Nevertheless, differences in the structure of the spatial patterns were observed among species. The closest temporal and spatial patterns were observed between chthamaloid barnacles. Meso-scale hydrographic features, approximated by SST, explained a significant proportion of the variance in recruitment and cyprid settlement of the chthamaloid species, and spatial analysis showed coincident decorrelation scales of about $35 \mathrm{~km}$ for SST and recruitment. In contrast, recruitment of the balanoid species was more idiosyncratic. While the meso-scale recruitment trend was significantly correlated to those of the chthamaloid species, balanoid recruitment did not show a clear spatial structure, was not associated to meso-scale variation in SST, and unlike the chthamaloids, local topographic features seemed to play a significant role in settlement of this species.

Settlement rates estimated in our study probably underestimate the actual rates of cyprid attachment to the substratum. Since cyprids usually metamorphose within 1 to $2 \mathrm{~d}$ after settlement (author's pers. obs.), the cyprids observed on the plate could have settled from a few hours and up to $2 \mathrm{~d}$ earlier. Moreover, there might be differences among species in the rates at which cyprids metamorphose after settling on the plate (e.g. Power et al. 1999). Without specific knowledge about the rates of cyprid metamorphosis, we simply divided by the total time that plates were exposed in the field to standardize across sites. Furthermore, studies suggest that cyprids of some species can have variable responses towards different settlement surfaces across sites (Raimondi 1988, Jenkins et al. 2000). Differential cyprid behavior would certainly influence any conclusion about spatial variation in settlement and recruitment of barnacles. In our study, the standard safety-walk surface of the plates allowed us to remove the variation resulting from differences in rock type and micro-scale heterogeneity (roughness) among study sites, which should help to reduce the effect of these factors on settlement behavior.
Our biweekly estimates of barnacle recruitment do not discriminate between the settlement process, defined as the rate at which larvae establish physical contact with the primary substrate (Keough \& Downes 1982, Jenkins et al. 2000), and the survival of the settlers for up to $2 \mathrm{wk}$, when plates were retrieved. Differential post-settler mortality produced by differences in local factors among sites (e.g. desiccation, predation on settlers, etc.), in addition to differential onshore larval transport, could therefore explain some of the observed among-site (here, local-scale) variability in recruitment. If such local factors also have a mesoscale structure (here, 10s of kilometers), they could explain some of the meso-scale trends observed in the recruitment of all barnacle species. However, the local topographic variables we measured at each site did not exhibit coherent meso-scale trends and were not correlated to meso-scale trends in recruitment of any species. Moreover, the spatial pattern of cyprid abundance, a more direct estimate of larval settlement rates, showed the same meso-scale trend, as well as positive among-site correlations with recruitment for all barnacle species, suggesting that the spatial structure of recruitment over scales of 10 s of kilometers is mostly the result of the settlement process. Although the recruitment-settlement relationship was positive, considerable differences in strength were observed among species, suggesting among-species differences in the importance of post-settlement mortality (Miron et al. 1999, Menge 2000, Jenkins et al. 2000). In our study, Notobalanus flosculus showed the lowest settlement-recruitment correlation, the weakest temporal persistence of the spatial pattern, lack of correlation with SST and no spatial structure of the pattern of rankings, suggesting that this species is either affected in different ways by meso-scale processes than the chthamaloid species, or that local site-specific factors play a more important role in settlement and recruitment. The positive correlation between the slope and orientation of the study site, and the residual variation in cyprid settlement are an indication of the influence of local factors. Field observations and settlement studies across tidal levels (S. A. Navarrete unpubl. data) have shown that, at the scale of a few meters, settlement of this species is less selective than that of chthamaloids and that post-settlers suffer massive mortality, apparently as a result of small-scale variation in desiccation or high temperature stress. Similar differences in settlement selectivity and post-settler mortality rates have been observed between coexisting barnacle species on other coasts (Strathmann \& Branscomb 1979, Delany et al. 2003). High and rapid mortality of post-settlers of $N$. flosculus could also explain why cyprid settlement, but not recruitment, was correlated to local topography. 
Average barnacle recruitment rates of Jehlius cirratus and Notochthamalus scabrosus were not significantly correlated to the mean adult abundance (percentage cover) observed at a site. However, recruitment of Notobalanus flosculus was highly correlated with adult abundance. A lack of significant correlations for chthamaloids suggests that post-recruitment processes (e.g. predation) largely determine adult cover (Navarrete \& Castilla 2003, see also Delany et al. 2003). The existence of a significant correlation for N. flosculus can be interpreted in 2 ways. (1) Larvae could choose to settle preferentially in areas where adults are more abundant. Some support for this explanation comes from field observations showing higher balanoid settlement in experimental $20 \times 20 \mathrm{~cm}$ plots with higher adult cover (S. A. Navarrete unpubl. data). (2) A larger adult population could produce more larvae and this in turn produces increased self-recruitment (Swearer et al. 2002). Further studies are needed to distinguish between these possibilities. In any case, positive correlations with adult abundance agree well with our results of increased effects of local factors for this species.

Recruitment and settlement of chthamaloid, and to a lesser extent of balanoid species, were higher in a neighbourhood of sites located towards the center of the study region, though this region is not necessarily the peak area of barnacle recruitment, when one considers a longer stretch of coastline. The spatial extension of this neighbourhood of high recruitment is about 25 to $30 \mathrm{~km}$, which corresponds well with the positive values of spatial autocorrelation for the temporal ranking of sites for Jehlius cirratus and Notochthamalus scabrosus (Fig. 7). It must be noted that the spacing between study sites was smaller in the center than in the northern and southern extremes of the study region. Both the extension (domain) and resolution (grain) of the study sites can affect the characterization of spatial pattern (Wiens 1989); however, our analyses after removing sites in the center of the region showed that the spatial pattern described is robust to the sampling arrangement. Moreover, balanoid and chthamaloid barnacles showed evidence of distinct spatial structure despite being subjected to identical sampling designs, suggesting that the results are likely to be due to bio-physical interaction, rather than methodological origin (see also Connolly \& Roughgarden 1998, Archambault \& Bourget 1999, Jenkins et al. 2000, Connolly et al. 2001, Navarrete et al. 2002).

The similitude in the spatial structure and scale in the recruitment of chthamaloid barnacles suggests that they may result from a common underlying process. When among-site post-settlement mortalities are similar, persistent ranking of sites has been interpreted as the effect of coastal geomorphology, which can in turn influence nearshore hydrographic processes responsi- ble for larval delivery to the shore (e.g. Caffey 1985, Connell 1985 along Australian coasts, Sutherland 1990 for the tropical zone, Navarrete et al. 2002 for the northern and central Chilean coast). In this study, sites of higher recruitment rates were located between Pelancura and Pt. Tralca, a zone of coastal recess with respect to the main orientation of the coastline (see Figs. 1 \& 6), suggesting a role of shoreline configuration on the spatial variation in barnacle recruitment. Moreover, differences in coastal orientation and the presence of capes and headlands (e.g. Pt. Curaumilla) are also associated with the spatial structure of upwelling dynamics in the zone (Fig. 2a). Wieters et al. (2003) and Narváez et al. (2004) describe an 'upwelling shadow' located in front of this neighbourhood of sites, which is responsible for the strong meso-scale differences in SST that were detected in this study through temperature loggers and from satellite images. Studies on this type of nearshore features in the Northern Hemisphere have suggested that upwelling shadows are areas of increased water retention produced by the presence of a prograde front and reduced offshore Ekman transport, which in turn may lead to increased concentration of some invertebrate larvae (Graham \& Largier 1997). Wing et al. (1995), Lagos et al. (2002) and Castilla et al. (2002) described a similar situation for the California and northern Chilean upwelling systems, respectively, suggesting the potential generality of this physical-biological feature along eastern boundary coastlines. While intertidal settlement might not be directly related to relaxation events (Vargas et al. 2004), the upwelling dynamics could determine the position and concentration of the larval pool across the region. Spatial differences in SST as a result of changes in upwelling regimes could also lead to shorter larval development times in upwelling shadows. It is, thus, likely that the meso-scale trends in recruitment of chthamaloid barnacles are related to the interaction between coastal geomorphology and nearshore upwelling dynamics (e.g. Ebert \& Russel 1988, Archambault \& Bourget 1999). This proposition is also supported by the significant correlations between the meso-scale trend in chthamaloid recruitment (and settlement) and SST, and by the coincident decorrelation scales of about $35 \mathrm{~km}$ shown by these variables.

Differences between chthamaloid and balanoid species could be related to differences in larval duration and feeding behavior. The scarce information available for Notobalanus flosculus suggest that larval duration of this species is similar to or longer than that of the chthamaloids (A. Olguín \& S. Navarrete unpubl. data), which does not agree with the pattern of larval duration between chthamaloid and balanoid species found along the coast of California (Brown \& Roughgarden 1985, Miller et al. 1989). Differences in the pattern of recruitment do not, therefore, seem to be 
related to simple differences in larval duration. More studies with $N$. flosculus are necessary to better establish larval duration and assess potential behavioral differences between its nauplii and those of chthamaloid species. Clearance rate studies have shown that advanced nauplii stages of $N$. flosculus feed on significantly larger particles and at significantly higher rates than nauplii of Jehlius cirratus (C. Vargas, P. Manriquez \& S. Navarrete unpubl. data). These differences could also lead to different behavior and spatial distribution of the larvae, and help explain differences in recruitment patterns.

In summary, our results show that the recruitment of intertidal barnacles is spatially structured within the coastline examined. Further studies are needed to evaluate the hypothesis that these patterns are the result of spatial differences in upwelling dynamics. Yet, the information has several implications for the design and future implementation of management or conservation strategies, since the neighborhood of high and persistent recruitment may also affect exploited species. For instance, for the study region and the spatial array of selected sites, results indicate that local populations situated $>35 \mathrm{~km}$ apart may represent independent samples of recruitment and environmental conditions; thus, protected areas should be spaced by at least this distance, after 1 fixed point is initially selected (Diniz-Filho \& Telles 2002). In the region, the ECIM marine reserve represents a long-term situation of unexploited populations (Castilla 1999), and could therefore be a good starting point for a network of marine reserves. Additional information on larval production at each site, together with the recruitment patterns reported here, can also be used to position reserves in areas of net source or sink of larvae (Botsford et al. 1998, Botsford 2001), depending on whether the goal of the protected area is to conserve threatened species or to increase fisheries yield.

Acknowledgedments. We are indebted to a number of friends and students who assisted us during this intensive field study, including O. Lúa, D. Narváez, A. Piñones, M. Pacheco, E. Wieters. N.A.L. acknowledges post-doctoral support from the Andrew Mellon Foundation through a grant to S.A.N. and J.C.C., and project INV-1-04-07 (UST). This study was funded by Fondap-Fondecyt grant 15001-0001 to the Center for Advanced Studies in Ecology and Biodiversity.

\section{LITERATURE CITED}

Archambault P, Bourget E (1996) Scale of coastal heterogeneity and benthic intertidal species richness, diversity and abundance. Mar Ecol Prog Ser 136:111-121

Archambault P, Bourget E (1999) Influence of the shoreline configuration on the spatial variation of meroplanktonic larvae, recruitment and diversity of benthic subtidal communities. J Exp Mar Biol Ecol 238:161-184
Botsford L (2001) Physical influences on recruitment to California current invertebrates populations on multiple scale. ICES J Mar Sci 10:1-11

Botsford L, Moloney C, Largier J, Hastings A (1998) Metapopulation dynamics of meroplanktonic invertebrates: the Dungeness crab (Cancer magister) as example. In: Jamieson G, Campbell A (eds) Proc North Pacific Symp Invertebrate Stock Assessment and Management. Can Spec Publ Fish Aquat Sci 125:295-306

Broitman B, Navarrete S, Smith F, Gaines S (2001) Geographic variation in southern Pacific intertidal communities. Mar Ecol Prog Ser 224:21-34

Brown S, Roughgarden J (1985) Growth, morphology, and laboratory culture of Balanus glandula larvae (Cirripedia: Thoracica). J Crustac Biol 5:574-590

Caffey H (1985) Spatial and temporal variation in settlement and recruitment of intertidal barnacles. Ecol Monogr 55: 313-332

Camus P, Lagos NA (1996) Variabilidad espacial y temporal del reclutamiento de ensambles de especies intermareales sésiles del norte de Chile. Rev Chil Hist Nat 69:193-204

Castilla JC (1999) Coastal marine communities: trends and perspectives from human-exclusion experiments. Trends Ecol Evol 14:280-283

Castilla JC, Steinmiller DK, Pacheco CJ (1998) Quantifying wave exposure daily and hourly on the intertidal rocky shore of central Chile. Rev Chil Hist Nat 71:19-25

Castilla JC, Lagos NA, Guiñez R, Largier J (2002) Plankton retention mechanism in the nearshore with emphasis on embayments: a review. In: Castilla JC, Largier J (eds) The oceanography and ecology of the nearshore and bays in Chile. Ediciones Universidad Católica de Chile, Santiago, p 179-203

Cleveland WS (1979) Robust locally weighted regression and smoothing scatterplots. J Am Stat Assoc 74:829-836

Connell J (1985) The consequences of variation in initial settlement vs. post-settlement mortality in rocky intertidal communities. J Exp Mar Biol Ecol 93:1-45

Connolly S, Roughgarden J (1998) A latitudinal gradient in northeast Pacific intertidal community structure: evidence for an oceanographically based synthesis of marine community theory. Am Nat 151:311-326

Connolly S, Menge B, Roughgarden J (2001) A latitudinal gradient in recruitment of intertidal invertebrates in the northeast Pacific Ocean. Ecology 82: 1799-1813

Delany J, Myers A, McGrath D, Riordan R, Power AM (2003) Role of post settlement mortality and 'supply-side' ecology in setting patterns of intertidal distribution in the chthamalid barnacles Chthamalus montagni and C. stellatus. Mar Ecol Prog Ser 249:207-214

Diniz-Filho JA, Telles MP (2003) Spatial autocorrelation analysis and the identification of operational units for conservation in continuous populations. Conserv Biol 16: 924-935

Ebert T, Russell MP (1988) Latitudinal variation in size structure of the west coast purple sea urchin: a correlation with headlands. Limnol Oceanogr 33:286-294

Eckert G (2003) Effects of planktonic period on marine population fluctuations. Ecology 84:372-383

Farrell T, Bracher D, Roughgarden J (1991) Cross-shelf transport causes recruitment to intertidal populations in central California. Limnol Oceanogr 36:279-288

Forde S, Raimondi PT (2004) An experimental test of the effects of variation in recruitment intensity on intertidal community composition. J Exp Mar Biol Ecol 301:1-14

Gaines S, Roughgarden J (1985) Larval settlement rate: a lead- 
ing determinant of structure in an ecological community of the marine intertidal zone. Proc Natl Acad Sci USA 82: 3707-3711

Graham W, Largier J (1997) Upwelling shadows as nearshore retention sites: the example of Monterrey Bay. Cont Shelf Res 17:509-532

Guichard F, Bourget E (1998) Topographic heterogeneity, hydrodynamics, and benthic community structure: a scaledependent cascade. Mar Ecol Prog Ser 171:59-70

Jeffrey CJ, Underwood AJ (2000) Consistent spatial patterns of arrival of larvae of the honeycomb barnacle Chamaesipho tasmanica Foster and Anderson in New South Wales. J Exp Mar Biol Ecol 252:109-127

Jenkins S, Aberg P, Cervin G, Coleman R and 9 others (2000) Spatial and temporal variation in settlement and recruitment of intertidal barnacle Semibalanus balanoides (L.) (Crustacea: Cirripedia) over a European scale. J Exp Mar Biol Ecol 243:209-225

Kaplan DM, Largier JL, Navarrete SA, Guiñez R, Castilla JC (2003) Large diurnal temperature fluctuations in the nearshore water column. Estuar Coast Shelf Sci 57:385-398

Keough MJ, Downes BJ (1982) Recruitment of marine invertebrates: the role of active larval choices and early mortality. Oecologia 54:248-352

Lagos NA, Barría I, Paolini P (2002) Upwelling ecosystems in northern Chile: integrating benthic ecology with oceanography through remote sensing. In: Castilla JC, Largier J (eds) The oceanography and ecology of the nearshore and bays in Chile. Ediciones Universidad Católica de Chile, Santiago, p 117-141

Legendre P (1993) Spatial autocorrelation: trouble or new paradigm? Ecology 74:1659-1673

Legendre P, Legendre L (1998) Numerical ecology, 2nd English edn. Elsevier Science, Amsterdam

LeTorneaux F, Bourget E (1988) Importance of physical and biological settlement cues at differents spatial scales by the larvae of Semibalanus balanoides. Mar Biol 97:57-66

Mantel N (1967) The detection of disease clustering and a generalized regression approach. Cancer Res 27:209-220

McKindsey CW, Bourget E (2000) Explaining mesoscale variation in intertidal mussel community structure. Mar Ecol Prog Ser 205:155-170

Menge BA (2000) Recruitment vs. post-recruitment processes as determinants of barnacle population abundance. Ecol Monogr 70:265-288

Menge BA, Berlow EL, Blanchette CA, Navarrete SA, Yamada SB (1994) The keystone species concept: variation in interaction strength in a rocky intertidal habitat. Ecol Monogr 64:249-286

Miller K, Blower S, Hedgecock D, Roughgarden J (1989) Comparison of larval and adult stages of Chthamalus dalli and Chthamalus fissus (Cirripedia: Thoracica). J Crustac Biol 9:242-256

Miron G, Boudreau B, Bourget E (1999) Intertidal barnacle distribution: a case study using multiple working hypotheses. Mar Ecol Prog Ser 189:205-219

Narváez D, Poulin E, Leiva G, Hernández E, Castilla JC, Navarrete SA (2004) Spatial variation of nearshore oceanographic conditions in central Chile. Cont Shelf Res 24: 279-292

Navarrete SA, Castilla JC (2003) Experimental determination of predation intensity in an intertidal predator guild: dominant versus subordinate prey. Oikos 100:251-262

Navarrete SA, Broitman B, Weiters E, Finke G, Venegas R, Sotomayor A (2002) Recruitment of intertidal invertebrates on the southeast Pacific: interannual variability and the 1997-1998 El Niño. Limnol Oceanogr 47:971-802

Nielsen KJ, Navarrete SA (2004) Mesoscale regulation comes from the bottom-up: intertidal interactions between consumers and upwelling. Ecol Let 7:31-41

Pineda J (1994) Spatial and temporal patterns in barnacle settlement rate along a southern California rocky shore. Mar Ecol Prog Ser 107:125-138

Pineda J (2000) Linking larval settlement to larval transport: assumptions, potentials, and pitfalls. Oceanogr East Pac 1: 84-105

Poulin E, Palma AT, Leiva G, Narváez D, Pacheco C, Navarrete SA, Castilla JC (2002) Avoiding offshore transport during upwelling events: the case of competent larvae of the gastropod Concholepas concholepas. Limnol Oceanogr 47 : 1248-1255

Power AM, Delany J, Myers AA, Riordan RM, McGrath D (1999) Prolonged settlement and prediction of recruitment in 2 sympatric intertidal Chthamalus species from southwest Ireland. J Mar Biol Assoc UK 79:941-943

Raimondi PT (1988) Rock type affect settlement, recruitment and zonation of the barnacle Chthamalus anisopoma Pilsbury. J Exp Mar Biol Ecol 123:253-267

Roughgarden J, Gaines S, Possingham H (1988) Recruitment dynamics in complex life cycles. Science 241:1460-1466

SHOA (2002) Tablas de marea de la costa de Chile. Servicio Hidrográfico y Oceanográfico de la Armada, Publicación $\mathrm{N}^{\circ} 3009$, Valparaíso

Sokal R, Oden N (1978) Spatial autocorrelation in biology. 1. Methodology. Biol J Linn Soc 10:199-228

Strathmann RR, Branscomb ES (1979) Adequacy of cues to favourable sites used by setting larvae of 2 intertidal barnacles. In: Stancyk SE (ed) Reproductive ecology of marine invertebrates. University of South Carolina Press, Columbia, SC, p 77-89

Strub T, Mesias J, Montecinos V, Rutland J, Salinas S (1998) Coastal ocean circulation off western South America. In: Robinson A, Brink K (eds) The sea, Vol 11. Wiley, New York, p 273-313

Sutherland J (1990) Recruitment regulates demographic variation in a tropical intertidal barnacle. Ecology 71(3):955-972

Swearer SE, Shima JS, Hellberg ME, Thorrold SR and 6 others (2002). Evidence of self-recruitment in demersal marine populations. Bull Mar Sci 70:251-271

Trexel J, Travis J (1993) Nontraditional regression analyses. Ecology 74:1629-1637

Vargas CA, Narváez DA, Piñones A, Venegas RM, Navarrete SA (2004) Internal tidal bore warm fronts and settlement of invertebrates in central Chile. Estuar Coast Shelf Sci 61: $603-612$

Venegas R, Ortiz V, Navarrete S (2000) Larval development of the intertidal barnacles Jehlius cirratus and Nothochtamalus scabrosus (Cirripedia: Chthamaloidea) under laboratory conditions. J Crustac Biol 20:495-504

Wartenberg D (1989) SAAP 4.3: spatial autocorrelation analyses program. Exter Softwares, New York

Wiens J (1989) Spatial scaling in ecology. Funct Ecol 3:385-397

Wieters EA, Kaplan DM, Navarrete SA, Sotomayor A, Largier J, Nielsen KJ, Véliz F (2003). Alongshore and temporal variability in chlorophyll a concentration in Chilean nearshore waters. Mar Ecol Prog Ser 249:93-105

Wing SR, Botsford LW, Largier JL, Morgan LE (1995) Spatial structure of relaxation events and crab settlement in the northern California upwelling system. Mar Ecol Prog Ser 128:199-211

Wing S, Botsford L, Ralston S, Largier J (1998) Meroplanktonic distribution and circulation in a coastal retention zone of the northern California upwelling systems. Limnol Oceanogr 43:1710-1721

Zar JH (1999) Biostatistical analysis, 3rd edn. Prentice Hall, Englewood Cliffs, NJ 